DOI: https://doi.org/10.15688/lp.jvolsu.2019.3.2

UDC 101.1:316

LBC 87.63

\title{
STRUCTURE, PROPERTIES AND FUNCTIONS OF POLITICAL MYTH
}

\author{
Alexey A. Zelykovsky \\ Lipetsk State Technical University, Lipetsk, Russian Federation
}

\begin{abstract}
The paper reveals the structure, properties and main functions of modern political myth, in addition, it analyzes the relationship between modern and archaic myths. The basis of modern political myths is rationalized and expressed in symbolic form mythological archetype. Despite the fact that archaic mythology as an integral system of worldview is rationalized, desacralized and destroyed, mythological archetypes retain their social significance. That is, political myths are the result of rationalization and symbolic interpretation of mythological archetypes. The article describes the main symbols-archetypes being invariably present in political discourse. For example, the hero archetype symbol is used to create heroic political myths. This group of myths is necessary for the formation of the image of a political leader. The representation of a political leader in accordance with the symbol-archetype of the hero significantly increases his capabilities and powers. The symbol-archetype of the Golden age is used to construct the image of the ideal social and political system. This archetype is especially actively exploited in various utopian and revolutionary projects. The symbol-archetype of the Great Mother, also actively used by modern mythology, forms ideas about their native land and country creating a sense of unity and cohesion. Since archetypal symbols retain their social significance, political myths, by reproducing them, perform important social functions. Shaping a special symbolic and semantic reality modern myths perform the main function meaning making. Modern political myths carry out their functions by acting on the unconscious level, thereby causing certain emotional experiences and pushing the masses to the required actions. Thus, it can be concluded that political myths are an integral component of modern social and political practice.
\end{abstract}

Key words: ideology, political myth, archaic myth, archetype, myth-making, mythologization.

УДК 101.1:316

ББК 87.63

\section{СТРУКТУРА, СВОЙСТВА И ФУНКЦИИ ПОЛИТИЧЕСКОГО МИФА}

\author{
Алексей Андреевич Целыковский \\ Липецкий государственный технический университет, г. Липецк, Российская Федерация
}

\begin{abstract}
Аннотация. В работе рассмотрены структура, свойства и основные функции современного политического мифа, кроме того, проанализирована взаимосвязь между современными и архаическими мифами. В основе первых находится рационализированный и выраженный в символической форме мифологический архетип. Несмотря на то что архаическая мифология как целостная система миропонимания рационализируется, десакрализируется и разрушается, мифологические архетипы сохраняют свою социальную значимость. То есть политические мифы являются результатом рационализации и символической интерпретации Әे мифологических архетипов. В статье анализируются основные символы-архетипы, неизменно присутствующие в политическом дискурсе. Например, символ-архетип героя используется для создания героических политических мифов. Данная группа необходима для формирования образа политического лидера. Репрезентация политического лидера в соответствии с символом-архетипом героя существенно увеличивает его возможности и полномочия. Символ-архетип золотого века используется для конструирования образа идеального общественного и политического строя. Особенно активно данный архетип эксплуатируется в различных утопических и революционных проектах. Символ-архетип Великой Матери, также активно используемый современной мифологией, формирует представления о своей родной земле и стране, чувство единства и сплоченности. Поскольку символы-архетипы сохраняют свою социальную значимость, политические
\end{abstract}


мифы, воспроизводя их, выполняют важные социальные функции. Создавая особую символическую и смысловую реальность, современные мифы выполняют главную функцию - смыслообразование. Свои функции современные политические мифы осуществляют, действуя на бессознательном уровне, вызывая тем самым определенные эмоциональные переживания и подталкивая широкие массы к выполнению требуемых действий. Таким образом, можно заключить, что политические мифы являются неотъемлемым компонентом современной социально-политической практики.

Ключевые слова: идеология, политический миф, архаический миф, архетип, мифотворчество, мифологизация.

Внимание к проблеме политической мифологии со стороны гуманитарных наук во многом обусловлено не только теоретическим интересом, но и сложившимся положением в социально-политической практике. Распад Советского Союза и отказ от государственной идеологии повлекли за собой крушение устоявшейся системы ценностей. В современных российских реалиях, характеризуемых отсутствием общепринятой идеологии и наличием различных социальных и политических мифов (в том числе и деструктивных), вопрос, касающийся новых духовных ориентиров, становится особенно актуальным. Специфика и функционирование современного политического мифа как мощного инструмента управления социально-политической практикой становится действительно значимой и востребованной темой исследования.

Внешне феномен политического мифа схож с феноменом идеологии. Зачастую это приводит к тому, что большинство исследователей не видят различий между политической мифологией и идеологией. В частности, Р. Барт стал одним из первых авторов, попытавшихся проанализировать механизмы функционирования современных мифов. В результате он сделал вывод о том, что практически любой текст может превратиться в миф. Р. Барт писал по этому поводу: «Поскольку миф - это слово, то мифом может стать все, что покрывается дискурсом» [Барт 2008, 265]. В процессе исследования современных мифов Р. Барт характеризовал их как идеологические системы, не имеющие отношения к традиционному мифу. По сути, данный подход отказывает в самостоятельном существовании политическому мифу.

Сходной позиции придерживается американский исследователь К. Флад. По его мнению, «мифологическим можно назвать любой политический текст в той степени, в какой он идеологически окрашен» [Флад 2004, 41]. При подобном понимании специфики политического мифа невозможно провести четкую границу между политической мифологией и идеологией. Связь между данными феноменами, безусловно, существует, однако сводить природу современных политических мифов исключительно к идеологии не вполне правомерно.

Для понимания особенностей и свойств современной политической мифологии необходимо обратиться к специфике мифологии архаической, поскольку сама терминология указывает на связь данных феноменов. Анализ сущностных особенностей архаической мифологии позволит прояснить отличительные черты современной политической мифологии как самостоятельного социального феномена.

Мифология для первобытного социума являлась инструментом, позволяющим накапливать, концептуализировать и транслировать социальный опыт. Мифология представляла собой смысловую систему, выполнявшую ряд важнейших социальных функций, тем самым конституирующую и поддерживающую социум. Концептуализация опыта происходила в форме мифологических сюжетов и образов, имеющих универсальное архетипическое значение. Архетипы - это устойчивые смысловые составляющие, неизменно присутствующие в мифологическом сюжете. Мифологические архетипы обобщают накопленный опыт, то есть становятся результатом познания окружающей реальности, и в то же время сами превращаются в парадигмы социального поведения.

В современной культуре понятие «архе-

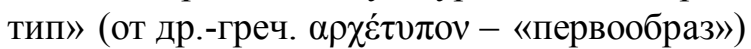
имеет широкий спектр различных значений, меняющихся в зависимости от контекста его использования. Наибольшее распространение данный термин получил в рамках аналитичес- 
кой психологии К.Г. Юнга, который понимал под архетипом некие универсальные структуры психики, содержащиеся на уровне коллективного бессознательного.

Однако нам хотелось бы дистанцироваться от подобного прочтения термина «архетип», избежав в дальнейшем возникновения возможных ассоциаций с концепцией К.Г. Юнга. В данной работе термин «архетип» будет использоваться не в психоаналитической трактовке. Мы будем отталкиваться от понимания мифологического архетипа, прежде всего как социокультурного феномена. Архетип представляет собой культурный и социальный опыт, накопленный бесчисленными поколениями людей, осмысленный и выраженный в структуре мифа в виде некоторых типичных образов (герой, золотой век, мировая ось) или типичных сюжетных моделей (космогония, биография героя).

В этом отношении используемое нами значение термина «архетип» близко по смыслу термину «мифологема», предложенному, кстати, тоже К.Г. Юнгом. В одной из своих работ, написанной в соавторстве с К. Кереньи, К.Г. Юнг пытается ответить на вопрос: по какой причине человек современного общества, безвозвратно утративший возможность непосредственного восприятия и переживания мифологии, постоянно обращается к ее сюжетам? Отвечая на поставленный вопрос, К.Г. Юнг обращается к материалу мифологии, к ее сюжетам. Согласно К.Г. Юнгу «традиция с незапамятных времен хранила этот материал в повествованиях о богах и богоподобных существах, героических битвах и странствиях в подземный мир - повествованиях («мифологема», пожалуй, - лучшее древнегреческое слово, выражающее их смысл), известных всем, но тем не менее далеких от окончательного оформления, ибо они являются источником для нового и нового творчества» [Юнг 2005, 7]. К.Г. Юнг делает справедливый вывод о том, что мифология полностью не исчезает; она сохраняется, но в «искусственной» форме. Мифологические образы, имевшие буквальное значение, в современной культуре представляют собой уже символические конструкты. Тем не менее, их универсальность говорит о непреходящем культурном и социальном зна- чении мифологии. Термин «мифологема», предложенный К.Г. Юнгом, демонстрирует универсальность мифологических мотивов и сюжетов и в то же время их способность к изменениям. Однако понятие мифологемы в том смысле, в котором его употребляет К.Г. Юнг, не вполне отвечает задачам данной работы, так как демонстрирует устойчивость и универсальность мифологических образов и сюжетов как психологических феноменов, но при этом не раскрывает их социокультурной природы и значения.

В контексте подхода к исследуемой проблеме более уместным является использование термина «архетип» в понимании мифолога и религиоведа М. Элиаде, трактовавшего мифологические сюжеты и образы как универсальные образцы для социальной активности человека архаического общества. По убеждению автора, миф «всегда имеет отношение к «созданию»: миф рассказывает, как что-то явилось в мир или каким образом возникли определенные формы поведения, установления или трудовые навыки; именно поэтому миф составляет парадигму всем значительным актам человеческого поведения» [Элиаде 2010, 28]. Таким образом, главная задача мифа состоит в том, чтобы предоставить человеку архаического социума шаблоны поведения.

К числу наиболее значимых мифологических архетипов можно отнести архетипы Хаоса и Космоса, архетип сакрального центра, или мировой оси, архетип героя, архетип золотого века. Архетипы Хаоса и Космоса формируют у архаического человека основополагающие представления о мироустройстве. Архетип Хаоса отражает представления о первоначальном состоянии Вселенной. Это архетип неорганизованного состояния мира. Хаос несет опасность, но в то же время в нем заключена огромная потенциальность, которую реализует Демиург, создающий из Хаоса гармоничную Вселенную. Космос - архетип упорядоченного состояния мира. В этом отношении архетип Космоса являет собой идею перехода к организованному социальному бытию.

Повествование о структурировании неоформленного Хаоса в упорядоченный Космос содержит важнейший мифологический архетип центра, или мировой оси. Пространство 
мифологическому мышлению представляется неоднородным, разделенным на две области: сакральный центр (мировая ось - «ахіs mundi») и периферия (враждебная территория). В мифологическом сюжете центр мира может быть представлен в виде священной горы, мирового древа, города или храма.

Ключевым элементом космогонического мифа выступает фигура божества-творца или культурного героя. Архетип культурного героя в мифологическом сюжете воплощается в виде демиуга - творца Вселенной, организатора и устроителя мира. Также данный архетип может быть представлен в виде первопредка основателя конкретной родовой общины или же человеческого рода в целом. Представление о данных двух категориях объединяет в себе образ культурного героя, который может изображаться и как создатель мира, и как прародитель человечества. Как созидатель и организатор мира, культурный герой добывает для человечества различные блага, основывает города и государства, устанавливает традиции и законы. Образ культурного героя является архетипом творческого, созидательного и организующего начала.

Процесс сотворения Космоса происходит в мифологическую эпоху, описываемую как время всеобщего благоденствия. Подобные мифологические сюжеты основываются на архетипе золотого века, описывающего идеал социального устройства.

Архетип Великой Матери - еще один важнейший мифологический архетип. Великая Богиня, или Великая Мать, является центральным персонажем в мифологии земледельческих цивилизаций, ее образ тесно связан с разнообразными культами плодородия и фактически представляет собой персонификацию земли.

Как целостная система мировоззрения мифология разрушается в процессе рационализации общественного сознания. Однако рационализированная мифология, претерпев существенные трансформации, тем не менее осталась значимой составляющей социальной реальности - об этом свидетельствует, в частности, феномен современной мифологии. Исходя из этого, можно заключить, что современное мифотворчество представляет собой процесс воспроизведения рационализиро- ванных символов-архетипов в рамках той или иной идеологической системы.

Среди основных свойств символа-архетипа можно назвать следующие: универсальность, символичность и интерпретируемость. Универсальность мифологических архетипов является фундаментальным свойством мифологии. В этом аспекте мифологию можно рассматривать как универсальную коммуникативную систему, понятную человеку любой культуры и эпохи. Как писал в одной из своих работ К. Леви-Строс: «Миф - это язык, но этот язык работает на самом высоком уровне, на котором смыслу удается, если можно так выразиться, отделиться от языковой основы, на которой он сложился» [Леви-Строс 2008, 243]. Несмотря на десакрализацию и рационализацию, мифологические архетипы, сохраняя свое универсальное социокультурное значение, реализуются в различных сферах духовной культуры. Определяющее отличие мифологического архетипа от архетипа, peaлизуемого в рамках современной политической мифологии, состоит в символической природе последнего.

Мифологические архетипы получают символическую трактовку, накладываясь на определенных исторических персонажей или конкретную историческую ситуацию, в зависимости от наличествующей социально-политической конъюнктуры. Содержащийся в архетипе смысл нуждается в символическом прочтении, поэтому символ-архетип предполагает широкий спектр возможных значений. Отсюда следует возможность разнообразных интерпретаций символа-архетипа. При этом необходимо подчеркнуть, что, говоря об устойчивости и универсальности символов-архетипов, мы не имеем в виду его внеисторический характер. Напротив, в конкретные исторические периоды, характеризуемые различной степенью рационализации общественного сознания, символы-архетипы приобретают соответствующие значения, однако их смысловая основа остается неизменной независимо от исторических, социально-политических и культурных условий.

Рационализированный архетип центра ложится в основу священной истории народа, демонстрируя истоки национальной культуры и идентичности. Процесс освоения простран- 
ства или заселения новых территорий мифологией изображается как Космогония - создание упорядоченного мира. В связи с этим обитаемое пространство всегда сакрально. В мифах божество или герой, основывая город или государство, сакрализует пространство, превращая его в центр мира. Аналогичным образом действует социум, основывая поселение, город или государство, и тем самым превращает неупорядоченную природную территорию в сакральное социальное пространство, в гармоничный социальный Космос.

Осознание собственной уникальности и идентичности практически невозможно без противопоставления центра и периферии. Мифологические архетипы центра (Космоса) и периферии (Хаоса) присутствуют в политическом мифе в виде диады «свои / чужие». Образ врага для политической мифологии востребован так же, как и образ центра.

Не менее значимым символом-архетипом, воспроизводимым политической мифологией, является символ-архетип культурного героя. Власть персонифицируется в образе лидера, поэтому символ-архетип героя является, пожалуй, самой востребованной и устойчивой составляющей политического дискурса. По мнению Н.Г. Щербининой, «самым политически влиятельным архетипом является Герой, который становится формой для репрезентации политического лидерства и власти в любой культуре и во все времена» [Щербинина 2011, 110]. Бесспорно, символ-архетип героя обладает огромным смысловым диапазоном и в политическом дискурсе может воплощаться в самых различных формах и образах. И.М. Суравнева и В.В. Федоров следующим образом описывают социально-политические функции героического политического мифа: «Героический миф - миф о рождении, смерти и возрождении героя, в котором воплощены чаяния поколений и сплетены высшая форма коллективности и высшая форма индивидуальности - постоянно циркулирует в любом обществе. Это мифы о власти, стоящей на страже Правды, о добром царе-герое или царе-мученике, о герое-избавителе (миф о сильной руке) и пр.» [Суравнева, Федоров 2008, 83].

Архетип золотого века - один из центральных архетипов, активно используемых в политическом дискурсе. Символ-архетип золотого века имеет разнообразные трактовки, являясь, в частности, основой для различных утопических и революционных проектов. Любопытно отметить, что сама этимология слова «революция» (от лат. revolutio - поворот, обращение) «намекает» о сущностной связи того или иного революционного проекта с мифологическим архетипом золотого века, декларируя возврат к утраченным идеалам и порядкам. То есть мифологический архетип золотого века современной мифологией используется для формирования идеала социальнополитического устройства.

В социально-политическом плане архетип Великой Матери трансформировался в довольно аморфный и пластичный образ родной земли, или Родины-Матери. Символ-архетип Великой Матери накладывался на место обитания социума, формируя особое мировидение. Сакрализация родной земли приводила к ощущению всеобщего родства, к чувству наличия особых невидимых, но нерушимых духовных уз. По наблюдению М. Элиаде, «между землей и порожденными ею формами существует магическая связь, некая симпатия. Все эти формы образуют в своей совокупности единую систему. Незримые нити, связывающие растительность, животных и людей данной местности с почвой, которая их породила, носит на себе и питает, были сотканы жизнью, пульсирующей и в самой Матери, и в ее созданиях» [Элиаде 2015, 224]. Мать-Земля, Родина-Мать - все эти словесные обороты проистекают из особого глубинного эмоционального переживания своей идентичности и национальной принадлежности. Как утверждает И.А. Исаев, «Мать-земля - архетип всякого территориально-почвеннически и расово-этнически ориентированного сознания» [Исаев 2015, 626]. Из этого следует особое место данного символа-архетипа в политическом дискурсе.

Из сказанного следует, что сущностную основу современных форм мифологии составляют рационализированные и выраженные в символической форме архетипы. Для мифологического мышления архетипы играли роль программ или сценариев социального поведения. С потерей мифологией статуса доминирующей формы общественного сознания ми- 
фологические архетипы тем не менее не потеряли своего социокультурного значения. Изменилась их форма и специфика восприятия, но не функции. Важнейшая задача мифа заключается в смыслообразовании. Благодаря современным мифам происходит формирование чувства национальной идентичности, возникает ощущение уникальности социума.

Таким образом, современное мифотворчество представляет собой воспроизведение символов-архетипов в политическом дискурсе. При этом можно выделить два вида мифотворчества: рациональную целенаправленную деятельность, осуществляемую в качестве части идеологической практики, и спонтанное воспроизведение символов-архетипов в общественном и политическом сознании. Данный процесс можно именовать мифологизацией. Исходя из сказанного, можно вывести определения вышеназванных понятий. Мифотворчество - это конструирование современных социальных и политических мифов, то есть целенаправленная и рациональная деятельность, заключающаяся в интерпретации каких-либо объектов, явлений и событий в соответствии с определенными мифологическими символами-архетипами и осуществляемая в рамках идеологической практики. Мифологизация - это неосознанная интерпретация объектов, явлений и событий в соответствии с мифологическими символами-архетипами, реализующаяся на уровне повседневности.

Современные социальные и политические мифы, воспроизводя перечисленные выше символы-архетипы, выполняют ряд важнейших функций. По аналогии с функциями архаической мифологии, функции современной социально-политической мифологии можно свести к четырем основным: онтологической, гносеологической, аксиологической и праксиологической. Онтологическая функция заключается в том, что политическая мифология, редуцируя сложную картину социальной реальности, предоставляет субъекту и социуму простые и понятные образы (свои и чужие, центр и периферия и т. д.). Современная мифология создает особую реальность - символическое смысловое пространство, в рамках которого происходит своеобразное истолкование наличествующей социально-политической практики. По замечанию Г.Г. Почепцова: «Эффективность воздействия мифа связана с заранее заданной его истинностью. Мифологическое не проверяется. Если ему нет соответствия в действительности, то в этом вина действительности, а не мифа. Тогда начинает препарироваться и подгоняться действительность, а не миф» [Почепцов 2001, с. 96]. В этом смысле можно сказать, что политическая мифология обладает и гносеологической функцией, так как она не только создает определенный образ реальности, но и соответствующим образом интерпретирует его, предоставляет набор смысловых шаблонов и стереотипов. Из этого следует аксиологическая функция современной мифологии. Смыслообразование - наиболее важная задача политического мифа, от успешного выполнения которой в конечном итоге зависит его жизнеспособность. Кроме того, в форме политического мифа происходит трансляция социокультурного опыта, что, в свою очередь, способствует самоидентификации субъекта. Отсюда следует праксиологическая функция политической мифологии, заключающаяся в обеспечении коммуникации, легитимации политической власти, а также социальной мобилизации.

Структуру политического мифа, таким образом, можно представить в следующем виде. Конституирующим элементом политического мифа являются мифологические символы-архетипы, благодаря которым происходит, во-первых, сакрализация политических процессов, во-вторых, трансляция ценностей. Кроме того, современный миф апеллирует к бессознательным пластам общественного сознания, вызывая эмоциональный отклик. Тем самым политический миф, в отличие от идеологии, значительно увеличивает свои мобилизационные и коммуникативные возможности, выполняя ряд важнейших функций. На основе всего сказанного можно вывести определение современного политического мифа. Политический миф - это система рационализированных и выраженных в символической форме мифологических архетипов, воспроизводимых в рамках какой-либо идеологической программы, транслирующих идеи и ценности и тем самым программирующих определенное социальное поведение. 


\section{СПИСОК ЛИТЕРАТУРЫ}

Барт 2008 - Барт Р. Мифологии / пер. с фр. С. Зенкина. М.: Академ. Проект, 2008.

Исаев 2015 - Исаев И.А. Избранные труды: в 4 т. Т. 1 М.: Проспект, 2015.

Леви-Строс 2008 - Леви-Строс К. Структурная антропология: пер. с фр. М.: Академ. проект, 2008.

Почепцов 2001 - Почепцеов Г.Г. Теория коммуникации. М.: Рефл-бук; Киев: Ваклер, 2001.

Суравнева, Федоров 2008 - Суравнева И.М., Федоров B.B. Феномен героизма. М.: Изд-во ЛКИ, 2008.

Щербинина 2011 - Щербинина Н.Г. Мифо-героическое конструирование политической реальности России. М.: Рос. полит. энцикл., 2011.

Флад 2004 - Флад К. Политический миф. Теоретическое исследование: пер. с англ. М.: Прогресс-Традиция, 2004.

Элиаде 2010 - Элиаде М. Аспекты мифа / пер. с фр. В.П. Большакова. М.: Академ. проект, 2010.

Элиаде 2015 - Элиаде М. Трактат по истории религий: пер. с фр. М.: Академ. проект, 2015.

Юнг 2005 - Юнг К.Г. Душа и миф. Шесть архетипов. М.: Харвест, 2005.

\section{REFERENCES}

Bart R., 2008. The mythology. Trans. with fr. S. Zenkina. Moscow, Academic Project.

Isaev. I.A., 2015. Selected Works. In 4 vols. Vol.1. Moscow, Prospectus.

Levi-Stros, 2008. Structural Anthropology: trans. with fr. Moscow, Academic project.

Pocheptsov G.G., 2001. Communication Theory. Moscow, Refl-Book; Kiev, Vakler.

Suravneva I.M., Fedorov V.V., 2008. Heroism phenomenon. Moscow, LKI Publ. House.

Shcherbinina N.G., 2011. Mythical and heroic construction of the political reality of Russia. Moscow, Russian political encyclopedia.

Flad K., 2004. Political myth. A theoretical research: trans. fr. eng. Moscow, Progress-Tradition.

Eliade M., 2010. Aspects of the myth. Trans. with fr. V.P. Bolshakova. Moscow, Academic Project.

Eliade M., 2015 Treatise on the History of Religions. Trans. with fr. Moscow, Academic project.

Jung K.G., 2005. Soul and the myth. Six archetypes. Moscow, Harvest.

\section{Information about the Author}

Alexey A. Zelykovsky, Candidate of Sciences (Philosophy), Associate Professor, Department of Philosophy, Lipetsk State Technical University, Moskovskaya St., 30, 398600 Lipetsk, Russian Federation, alts1085@mail.ru, https://orcid.org/0000-0002-2442-5463

\section{Информация об авторе}

Алексей Андреевич Целыковский, кандидат философских наук, доцент кафедры философии, Липецкий государственный технический университет, ул. Московская, 30, 398600 г. Липецк, Российская Федерация, alts1085@mail.ru, https://orcid.org/0000-0002-2442-5463 